AJIE - Asian Journal of Innovation and Entrepreneurship

(e-ISSN: 2477-0574; p-ISSN: 2477-3824)

Vol. 01, No. 03, September 2016

\title{
PEMBERDAYAAN DAN PENGEMBANGAN UKM SEBAGAI PENGGERAK EKONOMI DESA. (DESA HARJOBINANGUN, PAKEM, SLEMAN, DI YOGYAKARTA)
}

\author{
Lutfi Chabib $^{1 *}$, Yosi Febrianti' ${ }^{1}$, Abdul Hakim ${ }^{1}$, Muhammad Safarullah", \\ Bambang Subekti ${ }^{1}$ \\ ${ }^{1}$ Universitas Islam Indonesia, Yogyakarta-Indonesia \\ *lutfi.chabib@uii.ac.id
}

\begin{abstract}
Small and medium enterprise (SME/UKM) plays an important role in the national economic development, due its role in the economic growth and employee recruitment as well as its role in the development of product distribution. During the economic crysis that occured in this country a few years ago, which affected to the collapse of many big scale firms, Small and Medium Enterprise (SME/UKM) proved tougher in facing the crisis. Small and Medium Enterprise (SME/UKM) Dharma Karya is located in Harjobinangun, Pakem, Sleman, Daerah Istimewa Yogyakarta. Small and Medium Enterprise (SME/UKM) Dharma Karya has problems which are cannot grow as much as possible due to a limitation of facilities of production process so it can't be produce many product in maximum amount. The other problem is Small and Medium Enterprise (SME/UKM) Dharma Karya cannot sell their product in market because a limitation of skill and the product socialization. So that, KKN PPM UII is conducting a progam of procurement of required equipment and mentoring of entrepreneurship motivation, improvement of product quality, packaging products, quality of packaging, networking and cooperation. This program can improve the quality and productivity of Small and Medium Enterprise (SME/UKM) so that improve the rural economy.
\end{abstract}

Keywords : equipments, production, mentoring, packaging, networking

\begin{abstract}
ABSTRAK
Usaha kecil dan menengah (UKM) memainkan peran penting dalam pembangunan ekonomi nasional, karena perannya dalam pertumbuhan ekonomi dan perekrutan karyawan serta perannya dalam pengembangan distribusi produk. Selama krisis ekonomi yang terjadi di negara ini beberapa tahun yang lalu, yang mempengaruhi runtuhnya banyak perusahaan skala besar, Kecil dan Menengah (UKM) terbukti lebih tangguh dalam menghadapi krisis. Usaha Kecil dan Menengah (UKM) Dharma Karya terdapat di Harjobinangun, Pakem, Sleman, Daerah Istimewa Yogyakarta. Usaha Kecil dan Menengah (UKM) Dharma Karya memiliki masalah yang tidak bisa tumbuh sebanyak mungkin dikarenakan fasilitas terbatas dalam proses produksi sehingga tidak dapat menghasilkan banyak produk dalam jumlah maksimum. Masalah lain adalah (UKM) Dharma Karya tidak bisa menjual produk mereka di pasar karena keterampilan terbatas dan sosialisasi produk. Sehingga, KKN PPM UII melakukan progam untuk pengadaan peralatan yang dibutuhkan dan mentoring motivasi kewirausahaan, peningkatan kualitas produk, kemasan produk, kualitas kemasan, jaringan dan kerjasama. Program ini dapat meningkatkan kualitas dan produktivitas Usaha Kecil dan Menengah (UKM) sehingga dapat mendorong ekonomi pedesaan.
\end{abstract}


Kata kunci: peralatan, produksi, mentoring, kemasan, jaringan

\section{PENDAHULUAN}

Usaha Kecil Menengah (UKM) mempunyai peran yang strategis dalam pembangunan ekonomi nasional. Saat ini, UKM telah berkontribusi besar pada pendapatan daerah maupun pendapatan Negara Indonesia oleh karena selain berperan dalam pertumbuhan ekonomi dan penyerapan tenaga kerja juga berperan dalam pendistribusian hasil-hasil pembangunan (Bratakusumah dan Supriady, 2004). Dalam krisis ekonomi yang terjadi di Indonesia sejak beberapa waktu yang lalu yang menyebabkan banyak usaha berskala besar yang mengalami stagnasi bahkan berhenti aktifitasnya, sektor Usaha Kecil dan Menengah (UKM) terbukti lebih tangguh dalam menghadapi krisis tersebut. Mengingat pengalaman yang telah dihadapi oleh Indonesia selama krisis, kiranya tidak berlebihan apabila pengembangan sektor swasta difokuskan pada UKM, terlebih lagi unit usaha ini seringkali terabaikan hanya karena hasil produksinya dalam skala kecil dan belum mampu bersaing dengan unit usaha lainnya.

UKM (Usaha Kecil Menengah) selain sebagai salah satu alternatif lapangan kerja baru, sektor Usaha Kecil dan Menengah (UKM) terbukti lebih tangguh dalam menghadapi krisis tersebut (Ainuri, 2009). UKM juga berperan dalam mendorong laju pertumbuhan ekonomi pasca krisis moneter di saat perusahaanperusahaan besar mengalami kesulitan dalam mengembangkan usahanya. Saat ini, UKM telah berkontribusi besar pada pendapatan daerah maupun pendapatan Negara Indonesia.
UKM merupakan suatu bentuk usaha kecil masyarakat yang pendiriannya berdasarkan inisiatif seseorang. Sebagian besar masyarakat beranggapan bahwa UKM hanya menguntungkan pihak-pihak tertentu saja. Padahal sebenarnya UKM sangat berperan dalam mengurangi tingkat pengangguran yang ada di Indonesia UKM dapat menyerap banyak tenaga kerja Indonesia yang masih mengganggur (Putri, 2016).

Desa Harjobingangun, Sleman, D.I.Yogyakarta memiliki Usaha Kecil dan Menengah (UKM). Kelompok ini terdiri dari 20 orang yang tersebar di 5 pedukuhan dan semuanya bergerak di bidang makanan dan minuman ringan dan juga di beberapa padukuhan memiliki tanaman obat kelurga (TOGA) sebagai bahan pendukung dalam pembuatan minuman kesehatan seperti beras kencur,kunyit asam, dll.

\section{METODE PENELITIAN}

Metode pengumpulan data yang digunakan adalah wawancara. Wawancara merupakan percakapan antara dua orang atau lebih dan berlangsung antara narasumber dan pewawancara (Qonita dan Prnanto, 2015). Tujuan dari wawancara adalah untuk mendapatkan informasi yang tepat dari narasumber yang terpercaya. Wawancara dilakukan dengan cara penyampaian sejumlah pertanyaan dari pewawancara kepada narasumber dalam hal ini adalah Ketua UKM Dharma Karya untuk memperolah informasi berkaitan dengan masalah dan kendala yang dihadapi oleh para anggota UKM. Dari hasil wawancara tersebut, kemudian penulis melihat secara langsung proses 
produksi dari masing-masing anggota UKM Dharma Karya untuk mengamati sekaligus berdiskusi langsung mengenai keterbatasan dan permasalahan yang dimiliki oleh masing-masing anggota. Penulis juga melakukan pengujian terhadap produk yang telah diolah sedemikian rupa untuk memberikan masukan mengenai rasa, packaging, dan juga pemasaran produk tersebut. Hingga akhirnya penulis melakukan diskusi untuk menentukan program program apa saja yang akan disosialisasikan dan alat-alat apa saja yang menjadi prioritas untuk dibeli dan digunakan oleh UKM Dharma Karya. Selanjutnya, dilakukan survei harga dan kualitas di pasaran terhadap alat-alat yang akan dibeli. Penulis juga mengukur tingkat pemasaran yamg sudah dilakukan oleh UKM dan terakhir dilakukan pembelian setelah harga dan kualitas yang dimaksudkan telah terpenuhi.

\section{HASIL DAN PEMBAHASAN}

Pendampingan inovasi kualitas
kemasan produk

UKM Dharma Karya yang rata-rata produk dari UKM tersebut adalah olahan makanan dan minuman. Olahan makanan tersebut memiliki rasa yang enak dan bahan-bahan yang digunakan tidak mengandung zat-zat yang berbahaya sehingga sangat berpotensi untuk dijual secara lebih luas. Tetapi untuk dapat memasuki pasar yang lebih luas, banyak hal yang harus diperhatikan, salah satunya adalah kemasan atau packaging produk tersebut. Packaging dalam suatu produk haruslah memiliki standar dan menarik agar dapat dijual ke pasar yang lebih luas dan tidak kalah saing dengan produkproduk lainnya.

Selama ini anggota UKM Dharma Karya masih menggunakan cara packaging atau kemasan produk yang masih manual akibat dari itu daya minat konsumen untuk membeli berkurang dan juga banyak umur kemasan tidak dapat bertahan lama sehingga banyak dari produk yang dikembalikan atau return ke UKM masing masing.

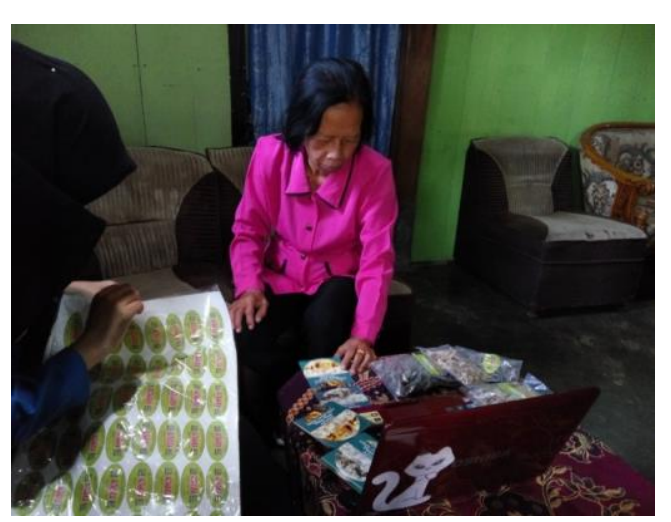

Gambar 1. Pendampingan inovasi kemasan produk

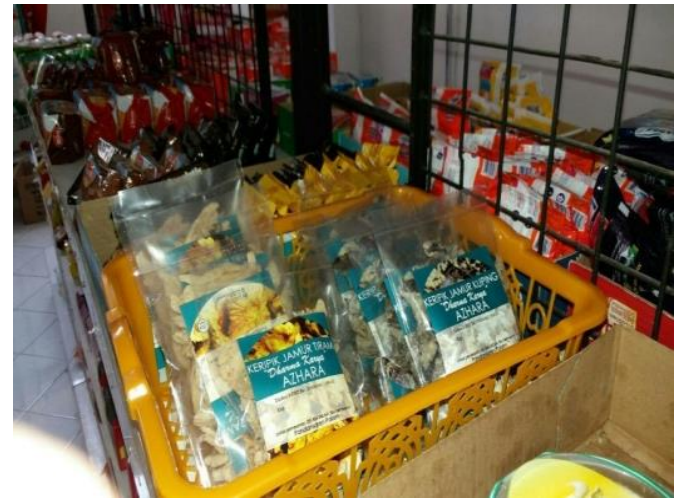

pangan dan bahaya yang mengancam kesehatan (BPOM, 2004).

Sosialisasi dan promosi halal diperlukan untuk memberikan edukasi bagi anggota UKM Dharma Karya. Melalui kegiatan sosialisasi produk halal 
dan P-IRT diharapkan para anggota UKM dan pelaku usaha dapat mengerti dan memahami tentang pentingnya produk halal dan P-IRT. Adapun beberapa program kegiatan sosialisasi produk halal dan P-IRT adalah sebagai berikut:

1. Memberikan edukasi tentang pentingnya produk halal.
2. Memberikan edukasi pentingnya memiliki perizinan usaha industri rumah tangga.

3. Sosialisasi tentang tantangan UKM di Masyarakat Ekonomi Asean (MEA).

4. Memberikan bantuan untuk membuat lisensi halal berkerjasama dengan HTREND UII.
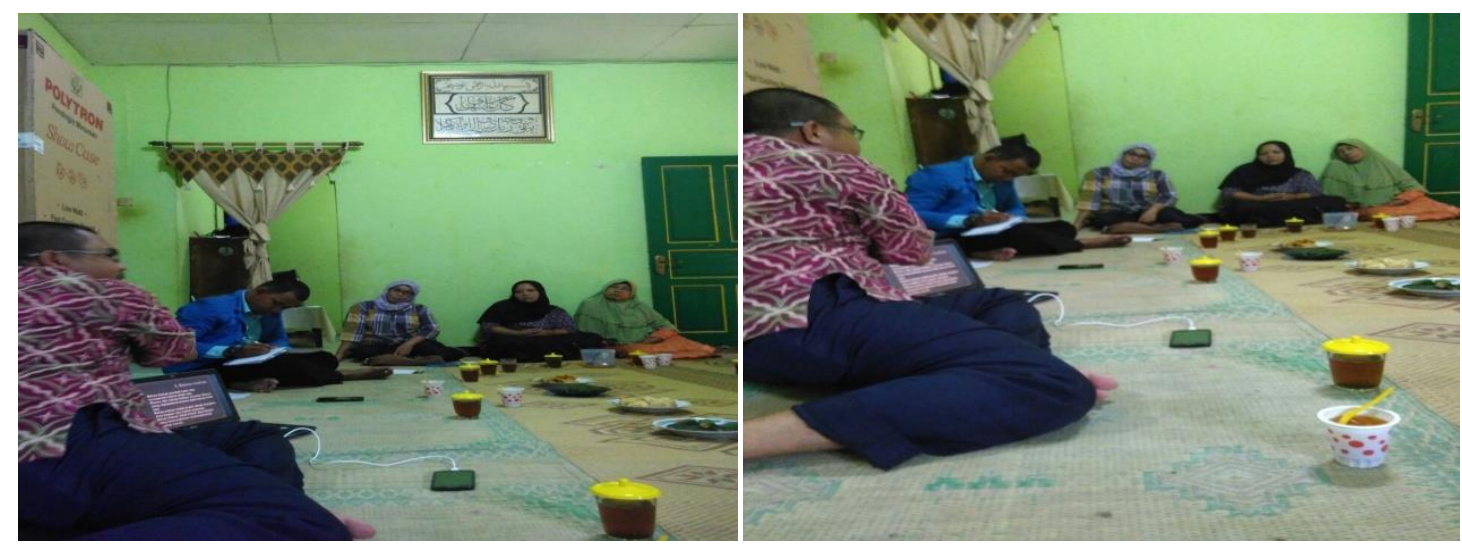

Gambar 2. Sosialisasi Produk Halal dan P-IRT

\section{Pendampingan kualitas produk melalui kualitas air}

Manfaat Air memang sangat banyak untuk kesehatan tubuh manusia. Tanpa air, manusia tidak akan bisa hidup dan sebagian besar tubuh manusia terdiri dari air dan juga air dapat bermanfaat bagi usaha usaha seperti UKM karena air merupakan sumber daya alam yang paling utama digunakan dalam prosesnya.

Tandon/tanki air berfungsi menampung air dari sumber air baku sebelum dialirkan ke dalam instalasi pipa di dalam rumah. Dengan tandon air, jika suatu saat pasokan air dari sumber air baku bermasalah, kita masih memiliki persediaan air untuk jangka waktu. Layout merupakan skema untuk menjelaskan detail-detail mengenai tandon baik dari jumlah debit air, kecepatan air, jenis penyaringan air yang digunakan dan titik koordinat tandon. Tujuan dan manfaat dari layout tandon air adalah sebagai berikut :

1) Tempat menampung air dari sumber air baku.

2) Sebagai sumber air untuk dapat di distribusikan untuk keperluan UKM Dharma Karya

3) Menjelaskan secara detail mengenai kualitas air.

4) Menjadi bukti fisik untuk pengajuan proposal kepemerintah.

5) Menjadi acuan utama untuk melihat apakah kualitas air benar sehat untuk digunakan dalam sebuah produksi makanan dan minuman UKM. 

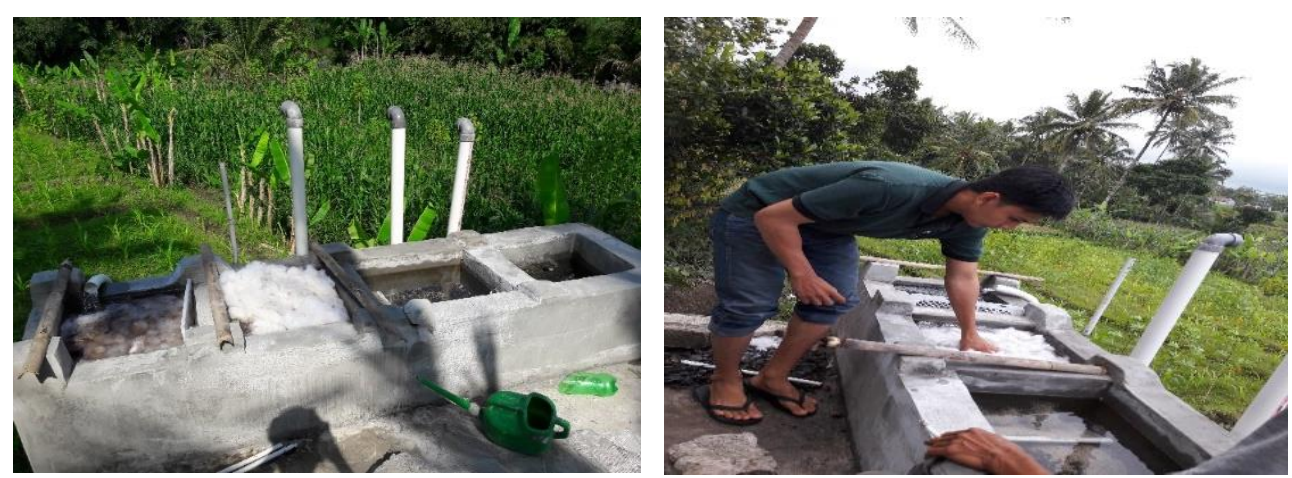

Gambar 3. Perbaikan kualitas tandon air

Pemanfaatan TOGA sebagai bahan alami produk makanan

Pemanfaatan pekarangan di pedesaan mempunyai banyak keuntungan terutama dalam meningkatkan pendapatan keluarga, misalnya sebagai warung hidup, lumbung hidup, dan apotek hidup, sehingga perlu dikembangkan secara intensif. Kenyaatan saat ini harga obat di pedesaan sangat tinggi, sering tidak tersedia, serta jauh dari apotek. Oleh karena itu penyediaan tanaman yang berfungsi sebagai obat di pekarangan sangat membantu dalam mengatasi masalah keluarga.

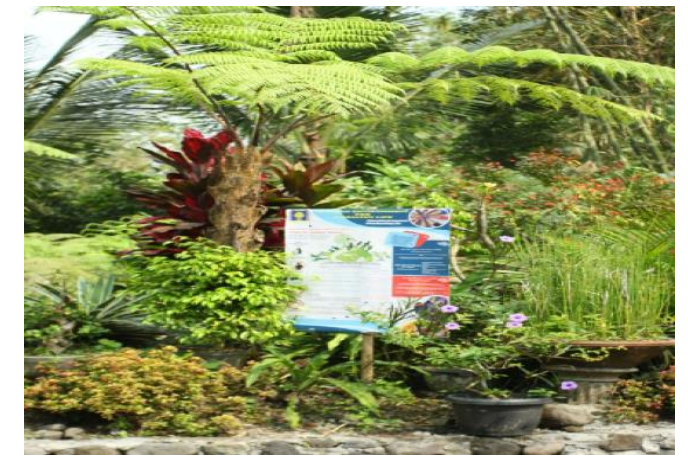

Gambar 4. Tanaman obat keluarga (TOGA) di Desa Harjobinangun
Di Desa Harjobinangun juga terdapat Usaha Kecil Menengah (UKM) Dharma Karya yang sudah memiliki banyak produk seperti snack basah dan kering, makan besar, $V C O$, keripik jamur, berbagai macam abon, serta jamu dalam bentuk sediaan cair. Jamu yang diproduksi berbagai macam seperti jamu beras kencur, kunyit asem, temulawak, dan umbi bit. Jamu ini sudah dikemas dalam bentuk botol kemasan dengan label yang kemudian dipasarkan ke beberapa daerah sekitar.
Sosialisasi dan praktek cara pembuatan serbuk jamu dari tanaman herbal sebagai salah satu solusi untuk memperpanjang masa konsumsi jamu produk UKM Dharma Karya sehingga dapat didistribusikan ke wilayah yang lebih luas. Sosialisasi dan praktek dilakukan bersama anggota UKM Dharma Karya serta dilakukan kerjasama dengan PSOH UII dalam melaksanakan program ini. Sosialisasi ini dilakukan di rumah anggota UKM. foto sosialisasi yang dilakukan sebagai berikut: 

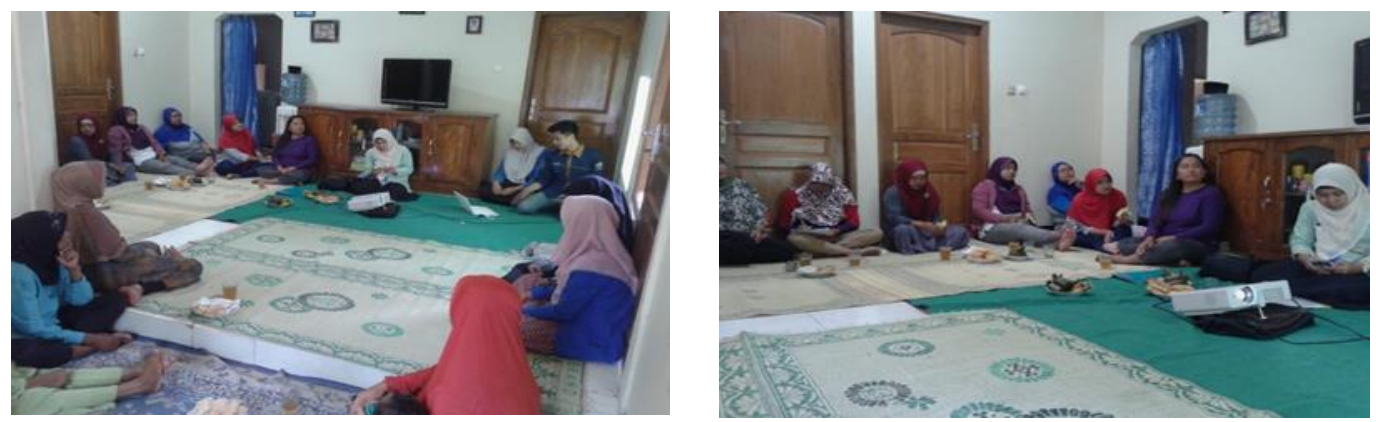

Gambar 5. Sosialisasi manfaat dari TOGA

\section{Perbaikan manajemen}
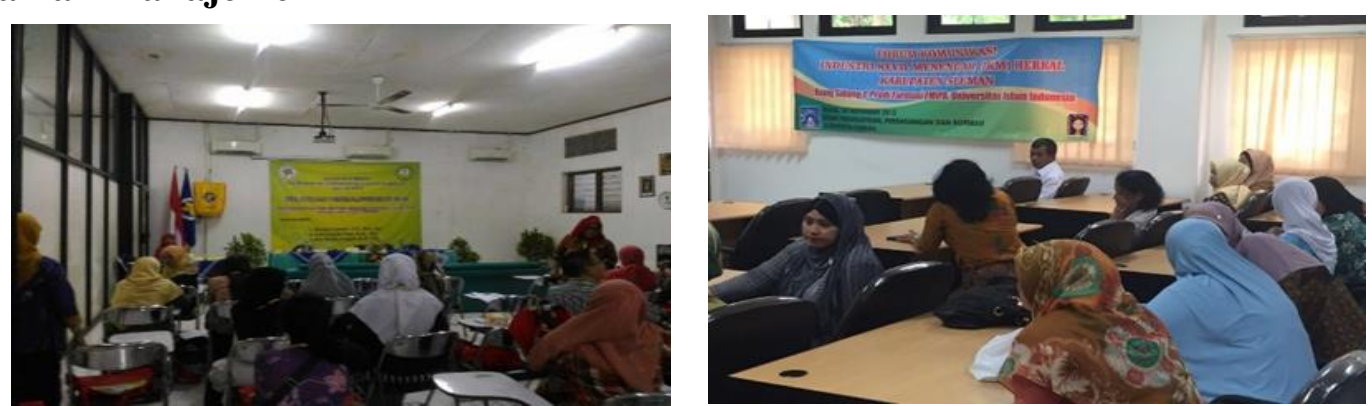

Gambar 6. Ibu-ibu mengikuti pelatihan kewirausahaan dan bussines plan

Perbaikan manajemen ini dilakukan dengan mendelegasikan beberapa ibu-ibu anggota UKM Dharma Karya dalam pembuatan bussnines plan dan pelatihan kewirausahan yang diselenggarakan oleh Politeknik Kesehatan Bhakti Setya Indonesia dan Fakultas MIPA UII. Tujuan dari diselenggarakan acara ini agar semua proses yang dilakukan oleh semua pelaku usaha UKM Dharma Karya dapat terarah sesuai dengan tujuan dari bussines plan yang sudah disusun dan juga melatih ibuibu UKM agar memliki jiwa entrepreneur yang dapat membantu keuangan rumah tangga dan juga menambah nilai ekonomi desa. Berikut dokumentasi pelatihan sebagai berikut:

Pengenalan pembuatan website dan pelatihan pemasaran melalui media online

Pemasaran didefinisikan sebagai telaah terhadap aliran produk secara fisis dan ekonomik dari produsen melalui pedagang perantara ke konsumen (Downey dan Erikson,1987). Pemasaran produk secara online saat ini banyak digunakan oleh para produsen barang ataupun reseller untuk memasarkan dan memperkenakan produknya ke kalangan masyarakat yang luas sehingga dapat meningkatkan nilai jual yang maksimal.

Program pembuatan blog didasarkan pada wawancara dengan ketua UKM Dharma Karya bahwa selama ini proses pemasaran yang terdapat di UKM masih menggunakan cara konvensional sehingga pemasaran produk belum luas dan belum ada media online untuk pemasaran berbasis online.

Alamat website yang digunakan adalah

http://dharmakaryaukm.wordpress.com.

Hasil pelatihan bagaimana menggunakan website dapat dengan cepat dikuasai oleh UKM Dharma Karya. 


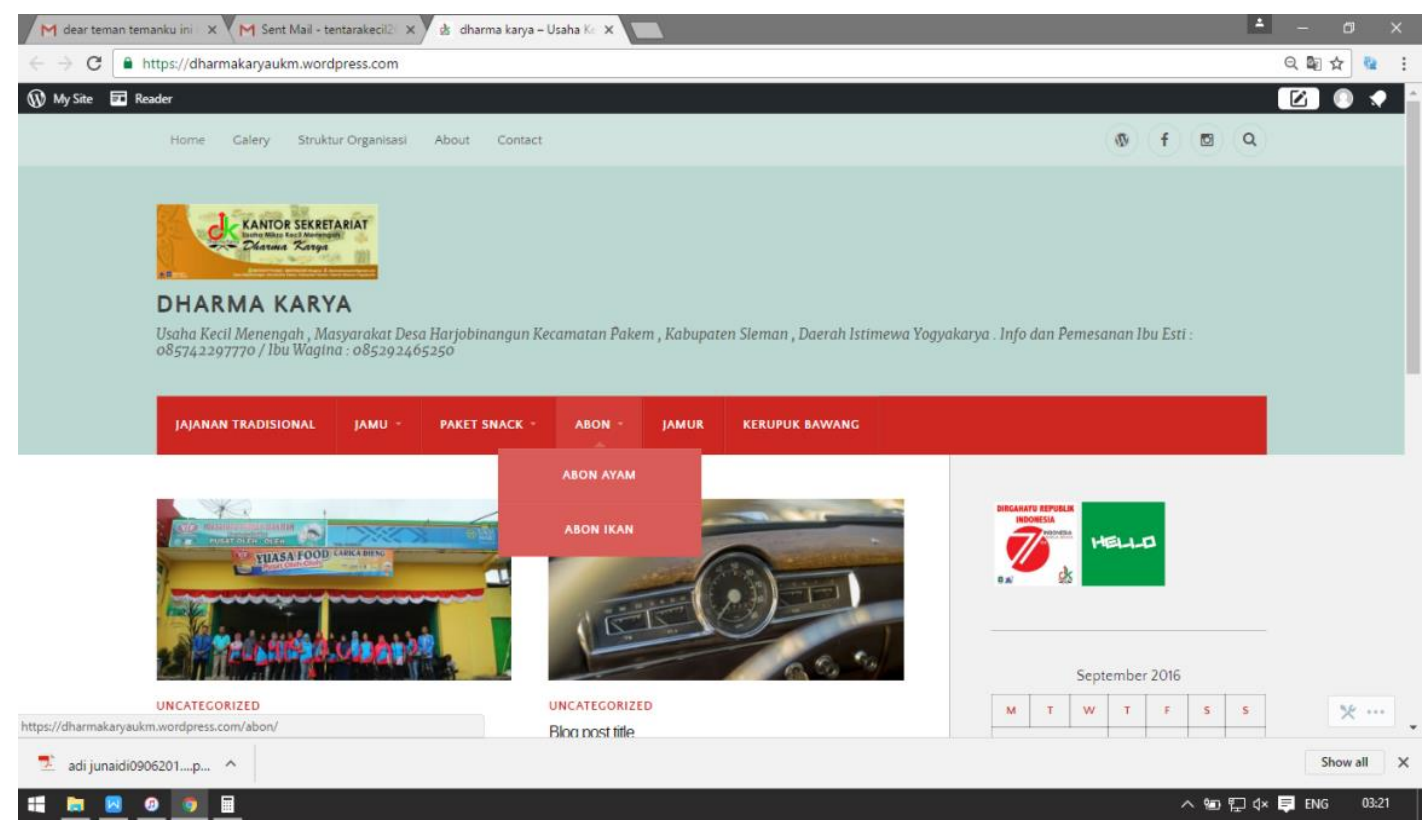

Gambar 7. Tampilan website UKM Dharma Karya

\section{KESIMPULAN}

Kegiatan yang dilaksanakan di Desa Harjobingangun menjawab seluruh permasalahan yang terjadi saat ini. Kegiatan-kegiatan yang telah dilaksanakan di UKM Dharma Karya adalah sebagai berikut: 1) pendampingan inovasi kualitas produk; 2) sosialisasi produk HALAL dan P-IRT; 3) pendampingan kualitas produk melalui kualitas air; 4) pemanfaatan TOGA sebagai bahan alami produk; 5) perbaikan manajemen di UKM Dharma Karya; 6) pengenalan pembuatan website dan pelatihan pemasaran melalui media online.

Kegiatan yang telah dilaksanakan perlu pendampingan secara kontinu terutama pada aktivasi website UKM dan perluasan pasarnya. Pendampingan ini bersifat memberdayakan sehingga UKM dituntut untuk mandiri dalam berusaha sehingga lambat laun pendampingan harus dikurangi tetapi tetap dilakukan pengawasan.

\section{DAFTAR PUSTAKA}

Qanita, A., Pranoto, N.H. 2015. Aplikasi Mesin Penepung Bahan Herbal untuk Meningkatkan Efesiensi Produksi pada Skala Home Industri. Lembaga Penelitian dan Pengabdian Kepada Masyarakat Universitas Sebelas Maret, Surakarta.

Downey, W.D., Erickson, S.P. Manajemen Agribisnis. Erlangga. Jakarta.

Badan Pengawas Obat dan Makanan RI. 2004. Amankan pangan dan bebaskan produk dari Bahan Berbahaya. Jakarta.

Ainuri, M. 2009. Nilai Ekonomi Modal Sosial Sebagai Media Rekaysa Difusi Teknologi Pada Sentra Industri Pangan Skala Kecil. Vol 29(4).

Riyadi, B., Supriady, D. 2004. Perencanaan Pembangun Daerah: Strategi Menggali Potensi Dalam Mewujudkan Otonomi Daerah. Jakarta.

Sintya, Putri, E. Usaha Kecil Menengah sebagai Potret UKM Indonesia. http://bisnis dan Investasi.com. 